\title{
Personal Loss and Grief Experiences of Healthcare Personnel in Pre- and Perinatal Care: A Review of Literature
}

\author{
Éva Zsák ${ }^{1}$, Teodóra Dömötör ${ }^{2} \&$ Katalin Hegedűs ${ }^{1}$ \\ ${ }^{1}$ Semmelweis University, Faculty of Medicine, Institute of Behavioural Sciences, H-1089 Budapest, Nagyvárad \\ tér 4. XX. emelet, Hungary \\ ${ }^{2}$ Karoli Gaspar University, H-1091 Budapest Kálvin tér 9, Hungary \\ Correspondence: Éva Zsák, Semmelweis University, Faculty of Medicine, Institute of Behavioural Sciences, \\ H-1089 Budapest, Nagyvárad tér 4. XX. emelet, Hungary. Tel.: 36-205-609-835. E-mail: \\ zsak.eva@phd.semmelweis-univ.hu
}

Received: April 2, 2019 Accepted: April 17, $2019 \quad$ Online Published: June 20, 2019

doi:10.5539/cco.v8n1p23 URL: https://doi.org/10.5539/cco.v8n1p23

\begin{abstract}
Pre- and perinatal loss and grief tend to be referred to as complicated grief denoting the experience of ongoing trauma. It is considered a burden for the affected parents, their families and the helping professionals alike. Yet this phenomenon remains an underrepresented field in analytical studies. Our aim is to systematically review the literature that deals with personal grief caused by pre- and perinatal loss - as experienced by healthcare staff. We shall present a comprehensive view of relevant international and national attitudes including existing grief management options. The above-mentioned complex issue deserves greater attention, which should result in the establishment of dynamic, up-to-date support programmes on all professional levels.
\end{abstract}

Keywords: perinatal loss, complicated grief, coping strategies, professional difficulties

What is known about the topic?

The personal and professional challenges experienced by healthcare personnel when facing perinatal loss have only been acknowledged recently.

This newly arisen interest has generated relatively few scientific publications, the majority of which cover study reports of individual researches, whereas a small number of them ventures to provide a systematic critical reading of theoretical and research-based studies of the last two decades approximately.

What does this article contribute to existing knowledge?

It is a freshly updated review with a time span until December 2018.

It sets out to systematically consider existent publications, focusing on the quality of individual studies and theoretical discussions, highlighting the ever-increasing global need to support caregivers in perinatal departments.

Propositions for practice and protocols

This article underlines the importance of support and the creation formation in the field of perinatal care, showing that the provision of more profound information and skills development training may significantly help healthcare professionals to face perinatal loss. On a more systematic level, the formation of national protocols and national guidelines is accentuated.

\section{Introduction}

The analysis of the loss and grief experiences of healthcare professionals - including the study of coping strategies and competencies to process these significant work-related events - is a relatively new field of research at international and domestic (Hungarian) levels. $(1,2)$ Although literature reviews and research studies on loss and grief have been produced extensively, assessments of the effect of loss and mourning on medical staff have seemingly been ignored so far, even though traumatic events influence their professional and personal attitudes as well. This problem is all the more significant if one considers the fact that grief and trauma caused by perinatal loss - if not assisted and confronted properly - may easily develop into a phenomenon of complicated 
grief. As such, it represents an increased burden for the affected families, their immediate environment and also for the professional staff helping them. This may probably be one of the greatest losses a person can suffer. The pain caused by death and mourning multiplies when an eagerly anticipated new life comes to an abrupt end, suddenly and unexpectedly. Moreover, even sepulchral problems may arise at the loss of infants who die in the womb or are stillborn.

The objective of the present study is to systematically review the literature regarding healthcare professionals affected by pre- and perinatal loss. We seek to obtain an overall view of the internationally acknowledged professional attitudes and solutions related to the impacts of pre- and perinatal infant death.

\section{Methodology}

\subsection{Selection Criteria Regarding the Articles Consulted in the Analysis}

This literary overview mainly includes studies which deal with the difficulties and/or attitudes related to grief and loss as experienced by those working in pre- and perinatal healthcare. Literary synopses and research studies are also in focus, offering tangible solutions to tackle the identified problems. Dissertations and doctoral theses, however, are excluded from the resources under scrutiny.

The majority of subjects in the studies are nurses (women only, underscoring an occupation that is vastly female-dominated) and medical doctors. Fewer studies deal with the doctors' attitudes and their experiences of loss. (3)

\subsection{Applied Research Methods and Databases}

The databases that we used include PubMed, Ovid MEDLINE, Ovid PsycINFO, Proquest, Scopus, CINHAL and the Hungarian Medical Bibliography (Magyar Orvosi Bibliográfia). Initially, the terms 'perinatal loss and grief' were the keywords that we applied to perform a search, then we narrowed it down by adding the words 'nurse' and 'doctor'. When searching the Hungarian database, we also applied the keyword 'perinatal loss' (perinatális veszteség). As our aim was to collect the most recent publications, the publication period was set between 2005 and 2018, allowing formerly published significant articles focusing on the topic of our interest to be included as well.

We also searched for information using specific websites of pre- and perinatal loss: http://www.perinatalhospice.org/; http://missfoundation.org/; http://www.ciaolapo.it/;

https://www.nowilaymedowntosleep.org/).

\section{Data Collection and Analysis}

The database search results are, as follows:

Table 1. Numbers of hits for keyword searches

\begin{tabular}{ll}
\hline Database: & No. of hits: \\
\hline Ovid MEDLINE & 611 \\
Ovid PsycINFO & 93 \\
Proquest & 1432 \\
Scopus & 167 \\
CINHAL & 78 \\
PubMed & 88 \\
MOB & 2 \\
\hline
\end{tabular}

When examining the findings, we narrowed down the results focusing on healthcare professionals' experiences of grief and loss, as follows:

Table 2. Number of hits of publications focusing on the grief and loss experiences of healthcare personnel

\begin{tabular}{ll}
\hline Database: & No. of hits: \\
\hline Ovid MEDLINE & 24 \\
Ovid PsycINFO & 3 \\
Proquest & 19 \\
Scopus & - \\
CINHAL & - \\
PubMed & 5 \\
MOB & 2 \\
\hline
\end{tabular}


It is important to emphasise that there are significant overlaps among different databases, thus the search results are not $100 \%$ accurate. Eventually, we identified 29 scientific publications that met our preset search criteria. The collected articles were firstly divided into categories on the basis of the healthcare professionals they targeted. Both doctors and nurses (midwives) were in the focus of 11 studies. There were 11 published researches concentrating on nurses, whereas doctors represented the exclusive subjects of only 4 analyses. Other professionals also present in pre- and perinatal care (i.e. psychologists, perinatal specialists, general practitioners) were not included in any international studies.

The qualitative analysis of the publications was performed according to the following criteria and order: author, place and time of publication, country, type of study, applied method(s), number of participants, field of activity, main research topics and results. We summarised our findings in a table.

The secondary diagnostic criterion was the publication date. As mentioned before, we strived to focus on and select for our overview the scientific writings of the last decade or so.

In terms of the limits of the literary overview, several publications concerning our topic of interest are healthcare recommendations or protocol measures, which are not available directly in the searched databases but only via specific homepages dedicated to pre- and perinatal loss:

(http://www.perinatalhospice.org/; http://missfoundation.org/;http://www.ciaolapo.it/; https://www.nowilaymedowntosleep.org/).

All in all, 29 studies were collected on the basis of our criteria. Pre-2005 publication dates were also considered if the works published then shared the focus of the present review. The categorisation of the articles - based on their nature - is, as follows: original publications: 23 , out of these research reports: 20, theoretical analyses: 3 ; literary overviews: 6 . According to the place of publication and the nationality of the authors, 11 publications come from the United States, 4 are British, 3 are Hungarian, 2 works per country belong to Italy, Ireland and Israel, while Australia, Brazil, Singapore and South-Africa have 1 material each.

The results of the research activity can be seen in Table 3 of the Appendix.

\section{Discussion}

A noteworthy tendency can be recognised in the publications, namely that growing attention is paid to healthcare professionals' personal and occupational problems arising from chronic distress, emotive involvement, personal grief and the non-appropriate elaboration of their feelings of grief and loss. A correlation can be identified between the help provided to bereaved families and the effects of personal involvement, the existence or lack of supervision and of expected training facilities. Should the latter ones become available on a regular basis, the elaboration of grief and loss may be much easier. $(1,2,3)$

Regarding earlier relevant analyses, the novelty of this study lies in the recognition that the acute and chronic experiences of loss impact not only the physical health of healthcare staff but their psychosocial well-being as well. $(4,5)$ Medical and nursing staff must be able to acknowledge that all experiences of loss affect their physical and mental health. (3) 'Cushioning' the psyche is mentioned as a quasi instinctive coping strategy against the experiences of loss by Gerow et al. (6) They put special emphasis on the necessity of appropriate elaboration of grief and loss for an adequate level of continuous professional performance. Gold et al (3) argue that such objectives can only be achieved via death education and competency development. This strategy enabled the examination of the problem on one of the largest scales: out of 1,500 doctors, more than 800 filled in and returned the questionnaire.

The researches show that the source of distress caused by loss and grief is differently experienced by nurses and doctors. While both professions consider help provided to patients as their highest priority, in the case of doctors proper decision-making regarding therapeutic solutions is equally essential(5), while for nurses caregiving and establishing a good relationship with individuals are of key importance, too. (1)

Most of the interviewed doctors claimed that perinatal death and loss represented significant emotional burden for them, some of them even considered changing their profession because of the experienced difficulties. $(5,7$, $8,9)$ This tendency can be recognised among nurses as well, although their personal attitudes are fairly dissimilar, as demonstrated previously. $(9,10)$ The analysed samples, except for the study of Roger et al from $2008(\mathrm{n}=890)$ $(10)$, are all rather short $(\mathrm{n} \leq 100)$, they mostly present results of researches conducted in a given institute $(1,6,8$, $10,11)$, focusing on the attitudes and issues of their own staff.

Two publications regarding Hungarian approaches to the problem should also receive critical attention. As demonstrated by the summary table, two decades passed between the two relevant researches, and no similar 
publication was issued in the meantime. $(2,12)$ The subjects in Török and Szeverényi's studies are obstetricians (2), while the research of Zsák et al also focuses on neonatologists, paediatricians, obstetricians, nurses, childcare specialists and psychologists (12). According to the results published to date, no significant change can be observed between the two Hungarian healthcare subject groups regarding the topic of our interest. The subject groups are characterised by very similar communicative, psychological and interpersonal difficulties as well as by similar attitudes concerning pre- and perinatal losses.

Interestingly, the majority of the relevant publications consist of reports of individual studies $(1,3,5,8,11,12$, $13,14,15,16,1718$ and 19), potentially highlighting the recent attention to the importance of the topic. It may also suggest increased awareness of the personal needs of healthcare professionals, expressed via local institutional practices. The burden of loss seems to be experienced in the same way regardless of people's geographical locations. Personal attitudes are investigated by qualitative research methods including IPA (eg. 5, 17), conducted via semi-structured interviews. A theoretical approach to grief and loss experiences is supplied in the articles by Mander (19) and Hogan (20), while linguistic analysis is also implemented to enter the core of the problem (21). Review of the recently published academic material is accomplished in different sources (22, 23 and 24) from culturally diverse environments, Singaporean, Hungarian and American, respectively.

\subsection{Proposals to Solve the Identified Problems}

Healthcare workers must be made aware of the potential health risks of untreated acute and chronic loss experiences. Likewise, they should be provided with information on the significance of supervision, psychosocial support and bereavement therapies. (1, 2, 3, 6, 7, 10, 11, 24, 25) Gold et al also suggest (3) group therapies - professional as well as personal -, highlighting the efficacy of this sort of bereavement support. Good personal relations with the patients and their families $(1,3,6,25)$ may be one of the ways of elaborating grief, while external help - via psychotherapy, mental hygiene or spiritual methods - can be considered a beneficial alternative. (1) Rogers et al (10) claim that providing continuous support (through external professionals) to PIC personnel after the death of each child is vital. Competencies and knowledge acquired from death education or thanatology appear to be other sources of adequate care, aiding the elaboration of subjective feelings. As per the findings of Gold et al and Gerow et al $(3,6)$, developing adequate coping strategies may contribute to the successful cultivation of relevant competencies.

For doctors, as it is revealed in the research with special focus on them, the opportunity to talk, either in a personal or professional ambiance (the latter one stands for $87 \%$ of the cases), is the mode to elaborate and ventilate their emotions. (3) On the other hand, they need individual coping strategies or competencies that - if applied repetitively - may help them move forward after each experience of loss. (25) The Brazilian publication emphasises the need for a protocol, and at the same time it underlines the importance of individual care and support. (11) The implementation of concrete supportive programmes is evaluated by Gallagher et al (26), Gardiner et al (27), Cartwright and Read (28), and McGrath (29).

\subsection{Strengths and Limitations}

The strength of this review lies in its ability to provide a comprehensive summary of the materials published in the last two decades dealing with the personal and professional attitudes of and difficulties experienced by healthcare operators in relation to perinatal loss and grief. The overview reveals an increasing need regarding the challenges that caregivers encounter, whether in private or in working conditions. The selection criteria may have been limited to a relatively great extent by only using the keywords 'prenatal' and 'perinatal'; as some research findings allow to suppose, other terminologies or approaches could also have been used for articles with a similar focus.

\section{Conclusion}

The results of this survey clearly demonstrate the significance and complexity of the main subject matter, namely, that more attention must be paid to the aftermath of traumas. This could include the provision of dynamic, accessible and up-to-date supervisory programmes available on each formative level of professional education. Although the publications consulted so far focus on the attitude of already skilled and active personnel, they also support the fact that early integrative educational programmes can be exceptionally beneficial. One of the greatest advantages of such opportunities is that they simultaneously centre on loss, grief and mourning as well as on the development of individual coping strategies, communication skills and emotional competencies in psychological, social and spiritual ways alike. On a more systematic level, the formation of national protocols and national guidelines is accentuated in our findings. Similarly to the previous solutions, these arrangements may greatly ease the difficulties and challenges that healthcare operators face when encountering cases of perinatal loss in their practices. 


\section{Declarations}

\section{Ethics approval and consent to participate}

Not applicable

\section{Consent for publication}

Not applicable

\section{Availability of data and material}

Not applicable

\section{Conflicts of interest}

The authors declare that they have no conflicts of interest

\section{Funding}

No funding was used for the preparation and composition of the article.

\section{Authors' contributions}

EZs collected the data, conducted the textual analysis and compiled the review, KH edited and TD corrected the manuscript. All authors read and approved the final manuscript.

\section{Acknowledgements}

Not applicable

\section{References}

Epstein, E. G. (2008). End of life experiences of nurses and physicians in the newborn intensive care unit. Journal of Perinatology, 28(11), 771-778. https://doi.org/10.1038/jp.2008.96

Kovácsné, T. Z, \& Szeverényi, P. (1995). A szülészek perinatális halálra adott interperszonális és intrapszichés válaszai. (Interpersonal and intrapsychic responses of obstetricians regarding perinatal loss) (In Hungarian) Orvosképzés, 6, 326-329.

Gold, K. J., Sen, A., \& Hayward, R. A. (2008). How physicians cope with stillbirth and neonatal death: a national survey of obstetricians. Obstetrics and Gynecology, 112(1), 29-34. https://doi.org/10.1097/AOG.0b013e31817d0582

Brunelli, T. (2005). A concept analysis: the grieving process for nurses. Nurs Forum, 40(4), 123-8. https://doi.org/10.1111/j.1744-6198.2005.00024.x

Nuzum, D., Meaney, S., \& O’Donoghue, K. (2014). The impact of stillbirth on consultant obstetrician gynaecologists: a qualitative study. BMJ Journals, 99(1), 1020-1028. https://doi.org/10.1111/1471-0528.12695

Gerow, L., Conejo, P., Alonzo, A., Davis, N., Rodgers, S., \& Domian, E. W. (2010). Creating a curtain of protection: nurses' experiences of grief following patient death. J Nurs Scholarsh, 42(2), 122-9. https://doi.org/10.1111/j.1547-5069.2010.01343.x

Ravaldi, C. (2014). La morte perinatale. Aspetti psicologici del lutto e strumenti d'intervento (Perinatal death. Psychological aspects of bereavement and clinical practice). Rivista Sperimentale di Freniatria, 3, 67-76. https://doi.org/10.3280/RSF2014-003006

Modiba, L. (2008). Experiences and perceptions of midwives and doctors when caring for mothers with pregnancy loss in a Gauteng Hospital. Health Sa Gesondheid, 13(4), 29-40. https://doi.org/10.4102/hsag.v13i4.402

Puia, D. M., Lewis, L., \& Beck, C. T. (2013). Experiences of obstetric nurses who are present for a perinatal loss. Journal of Obstetrics Gynecology Neonatal Nursing, 42(3), 321-331. https://doi.org/10.1111/1552-6909.12040

Rogers, S., Babgi, A., \& Gomez, C. (2008). Educational interventions in end-of-life care: Part 1: An educational intervention responding to the moral distress of NICU nurses provided by an ethics consultation team. Advances in Neonatal Care, 8(1), 56-65. https://doi.org/10.1097/01.ANC.0000311017.02005.20

Pastor-Montero, S. M., Romero-Sánchez, J. M., Paramio-Cuevas, J. C., Hueso-Montoro, C., Paloma-Castro, O., Lillo-Crespo, M., ... Frandsen, A. J. (2012). Tackling perinatal loss, a participatory action research approach: research protocol. $J$ Adv Nurs. 68(11), 2578-85. https://doi.org/10.1111/j.1365-2648.2012.06015.x 
Zsák, É., Kovácsné, T. Z., \& Hegedűs, K. (2015). A perinatalis veszteségek és intrauterin magzati halálozások aktuális szakmai gyakorlatának, valamint a szakemberekre gyakorolt hatásainak vizsgálata. (Analysis of actual practices of perinatal and intrauterine fetal death, and of their effects on healthcare professionals) (In Hungarian). Orvosi Hetilap, 156(29), 1174-1178. https://doi.org/10.1556/650.2015.30199

Hamama-Raz, Y. et al. (2016). Comorbidity of Post-traumatic Stress Symptoms and Depressive Symptoms among Obstetric Nurses with Perinatal Death Exposure. Israeli Journal of Psychiatry Related Sciences, 53(2), 58-62.

Ben-Ezra M. et al. (2014). The impact of perinatal death on obstetrics nurses: a longitudinal and cross-sectional examination. Journal of Perinatal Medicine, 42(1), 75-81. https://doi.org/10.1515/jpm-2013-0071

McCreight, B. S. (2005). Perinatal grief and emotional labour: a study of nurses' experiences in gynae wards. International Journal of Nursing Studies, 42(4), 439-48. https://doi.org/10.1016/j.ijnurstu.2004.07.004

McNamara, K. et al. (2017). Healthcare professionals' response to intrapartum death: a cross-sectional study. Arch Gynecol Obstet. 295(4), 845-852. https://doi.org/10.1007/s00404-017-4309-9

McNamara, K. et al. (2018). Intrapartum fetal death and doctors: a qualitative exploration. Acta Obstet Gynecol Scand, 97(7), 890-898. https://doi.org/10.1111/aogs.13354

Wallbank, S., \& Robertson, N. (2013). Predictors of staff distress in response to professionally experienced miscarriage, stillbirth and neonatal loss: a questionnaire survey. International Journal of Nursing Studies, 50(8), 1090-7. https://doi.org/10.1016/j.ijnurstu.2012.11.022

Mander, R. (2009). Good grief: staff responses to childbearing loss. Nurse Education Today. 29(1), 117-23. https://doi.org/10.1016/j.nedt.2008.07.005

Hogan, L. A. (2017). Personal Grief in the Professional World. Journal of Palliative Medicine, 20(3), 303-304. https://doi.org/10.1089/jpm.2016.0426

Gandino, G. et al. (2017). The impact of perinatal loss in maternity units: A psycholinguistic analysis of health professionals' reactions. Journal of Health Psychology. https://doi.org/10.1177/1359105317727841

Shorey, S. et al. (2017). The experiences and needs of healthcare professionals facing perinatal death: A scoping review. International Journal of Nursing Studies, 68, 25-39. https://doi.org/10.1016/j.ijnurstu.2016.12.007

Zsak, E., \& Hegedus, K. (2017). Veszteségélmények, gyász, megküzdési stratégiák a prae- és perinatalis ellátásban (Experiences of loss, grief, coping strategies in pre- and perinatal care). Lege Artis Medicinae, 27(03).

Browning, D., \& Solomon, M. (2005). The initiative for paediatric palliative care: an interdisciplinary educational approach for healthcare professionals. Paediatric Nursing, 20(5), 326-334. https://doi.org/10.1016/j.pedn.2005.03.004

Limbo, R., \& Kobler, K. (2010). The tie that binds: Relationships in perinatal bereavement. MCN: The American Journal of Maternal/Child Nursing, 35(6), 316. https://doi.org/10.1097/NMC.0b013e3181f0eef8

Gallagher, K., Cass, H., Black, R., \& Norridge, M. (2012). A training needs analysis of neonatal and paediatric health-care stuff in a tertiary children's hospital. International Journal of Palliative Nursing, 18(4), 197-201. https://doi.org/10.12968/ijpn.2012.18.4.197

Gardiner, P. A. et al. (2016). Evaluation of an international educational programme for health care professionals on best practice in the management of a perinatal death: IMproving Perinatal mortality Review and Outcomes Via Education (IMPROVE). BMC Pregnancy and Childbirth, 16, 376. https://doi.org/10.1186/s12884-016-1173-8

Cartwright, P., \& Read, S. (2005). Working with practitioners to develop training in perinatal loss and bereavement: Evaluating three workshops. Nurse Education in Practice, 5, 266-273. https://doi.org/10.1016/j.nepr.2005.01.004

McGrath, J. M. (2011). Neonatal nurses: what about their grief and loss?. The Journal of Perinatal and Neonatal Nursing, 25(1), 8-9. https://doi.org/10.1097/JPN.0b013e318208cbf6 


\section{Appendix}

Table 3. Literary review regarding pre- and perinatal losses and the grief, death attitudes of healthcare professionals (table summary)

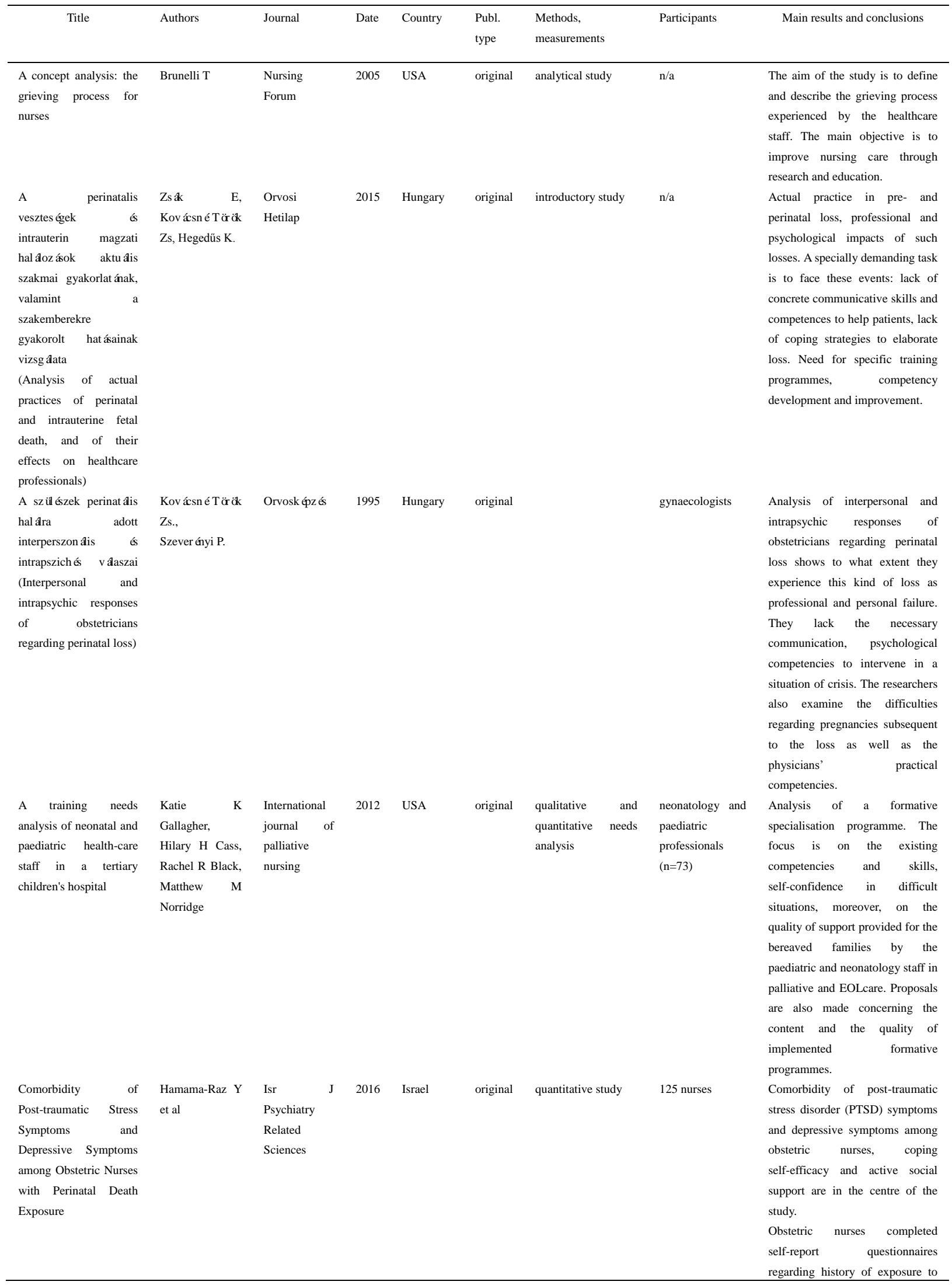




$\begin{array}{lllllll}\text { Creating a curtain of } & \text { Gerow } \quad \text { L, J Nursing } 2010 & \text { USA } & \text { original } & \text { semi-structured } & 11 \text { nurses } \\ \text { protection: nurses' } & \text { Conejo P, Scholarship. } & & \text { interviews and use } \\ \text { experiences of grief } & \text { Alonzo A, Davis } & & \text { of } \\ \text { following patient death } & \mathrm{N} \text {, Rodgers S, } & & \text { phenomenological } \\ & \text { Domian EW. } & & \text { concepts }\end{array}$

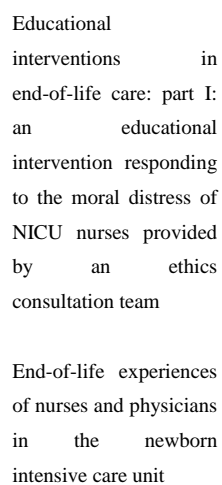

\begin{tabular}{|c|c|c|c|c|c|c|c|}
\hline $\begin{array}{l}\text { Rogers S, } \\
\text { Babgi } \\
\text { Gomez C }\end{array}$ & $\mathrm{A}$, & $\begin{array}{l}\text { Advances in } \\
\text { Neonatal Care }\end{array}$ & 2008 & USA & original & $\begin{array}{l}\text { quantitative pre-test } \\
\text { intervention, } \\
\text { post-test project in a } \\
\text { single group, during } \\
\text { a specialization } \\
\text { course }\end{array}$ & $\begin{array}{l}82 \text { nurses at } \\
\text { NICU }\end{array}$ \\
\hline Epstein EG & & J Perinatology & 2008 & USA & original & $\begin{array}{l}\text { semi-structured } \\
\text { interviews with the } \\
\text { participants, } \\
\text { demographic data } \\
\text { analysis }\end{array}$ & $\begin{array}{l}21 \text { nurses } \\
11 \text { physicians at } \\
\text { NICU }\end{array}$ \\
\hline
\end{tabular}

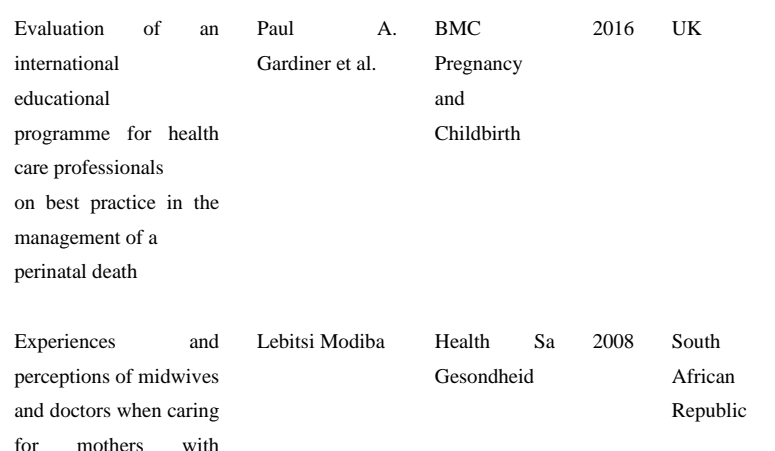

original in-depth interviews obstetricians

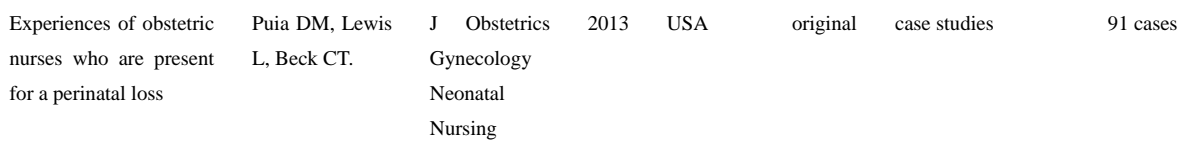

traumatic events, PTSD symptoms and depressive symptoms.

Stress intervention, supportive clinical environments and educational programmes among obstetric nurses should be promoted.

The influence of personal and professional relations, of previous loss experiences, the link between personal coping strategies and the provided support as well as the need to elaborate the experiences are in the focus. The possibility to work only with a 'protective curtain'.

Understanding grieving process and improving coping strategies may help to acquire required competencies.

In the pre- and postintervention project the focus was on ethical, legal and symptomatic problems. Painkilling, spirituality and compassion fatigue were as significant as communicative and intercultural problems. NICU staff need continuous support, following every single child death, with external help.

'Create the best possible experience for parents'. Bonds, preparation to the end-of-life experience, memory making are the themes of both examined groups. The members defined their own roles and tasks differently regarding perinatal loss. Personally moral distress, parental competencies and consent to autopsy are significant.

original

evaluation of an educational pre- and post evaluation, 890 programme set up participants, for staff of obstetric questionnaires and neonatology dept.

The demonstrated formative programme focuses on stillbirth. The objective is skills and competency development, in international settings as well.

\footnotetext{
The observed non adequate attitudes are due to inadequate levels of skills and competences among the staff members. All these generate sensations of powerlessness, tension and frustration in them. Need for well planned, supporting formative programmes.

Professional problems related to perinatal and child-loss: 'survive the shift', feelings of grief and loss, frustration, providing adequate support, elaboration of grief, living memorable experiences. Need for supervision.
} 


\begin{tabular}{lllllll}
\hline Experiences with & Pastor Montero & Rev Lat Am 2011 & Brazil & original & interviews, \\
perinatal loss from the & SM, Romero & Enfermagem. & & & qualitative study \\
health professionals' & Sánchez JM, & & & \\
perspective & Hueso Montoro & & & \\
& C, Lillo Crespo & & \\
& M, Vacas Jaén \\
& AG, Rodríguez \\
& Tirado MB.
\end{tabular}

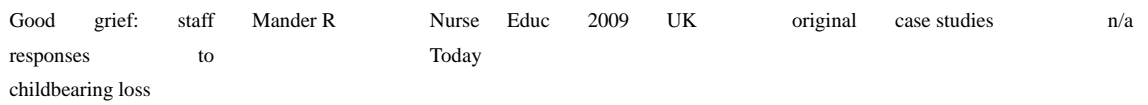

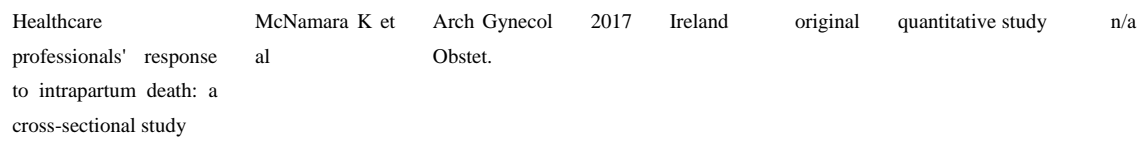

Intrapartum fetal death and doctors: qualitative exploration
McNamara K, Acta Obstet 2018 Ireland Meaney S, Gynecol O'Donoghue K Scand original

questionnaire, sent by post in 3 copies, with focus on experiences and attitudes regarding perinatal loss

original IPA out of 1500 , randomly selected American obstetricians 804 (54\%) filled in and sent back the complete questionnaire

0 physicians

\footnotetext{
La morte perinatale. Aspetti psicologici del Ravaldi, Claudia Rivista Sperimentale original review di Freniatria

The aim was to identify coping strategies in perinatal loss. The focus is on the applied healthcare procedures, the emotions of the healthcare staff, on the beliefs and concepts of grief and loss. Insufficient level of knowledge, lack of competencies and skills generate feelings of incapacity, powerlessness and frustration in professionals. Appropriate formative programmes and guidelines are required to resolve problems.

Emotional implications of staff in case of loss in perinatal circumstances are in the focus of the paper. While education is a way to help staff grief, it still remains a very sensitive situation in need of further attention.

Document the experiences of intrapartum death (IPD), to identify opinions, education and suitable support strategies.

A questionnaire study, with open and closed questions, was developed and set in a tertiary maternity hospital. Main qualitative themes from the data: the personal impact of IPDs, implications for professional practice and future patient care, and the importance on non-judgemental support.

$75 \%$ of the interviewed physicians consider perinatal loss as an emotional burden, approx. $10 \%$ have already thought of changing profession because of this. Main coping strategies are conversations with colleagues $(87 \%)$, family or friends $(56 \%)$. Thanatology courses are help to provide adequate support and to elaborate their own feelings.

In-depth qualitative exploration of the attitudes and responses obstetricians have following direct involvement with intrapartum fetal death. Obstetricians were profoundly and negatively affected by a personal involvement with an intrapartum death. Doctors directly involved in an intrapartum death are the second victims. Effective emotional support intervention is important.

Negative feelings due to pre- and perinatal loss, frustration coming from not providing needed care and support, experiencing professional failure and attitude towards death are the most significant factors in healthcare professionals' care-giving. 


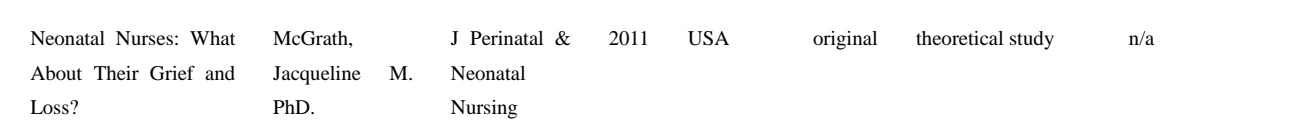

\begin{tabular}{|c|c|c|c|c|c|c|c|c|}
\hline $\begin{array}{l}\text { Perinatal grief and } \\
\text { emotional labour: a } \\
\text { study of nurses' } \\
\text { experiences in gynae } \\
\text { wards }\end{array}$ & McCreight BS & $\begin{array}{l}\text { Int J } \\
\text { Stud }\end{array}$ & Nurs & 2005 & UK & original & quantitative study & 14 nurses \\
\hline
\end{tabular}
Professional World distress in response to professionally

experienced

miscarriage, stillbirth and neonatal loss: a questionnaire survey

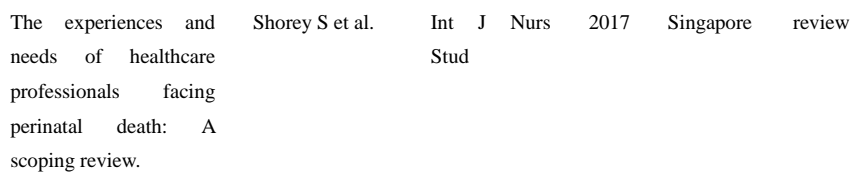

Psychological overview with methodological proposals for problem solving.

The focus is on the high level of emotional involvement of the healthcare staff, on the specific characteristics of their experiences of loss, moreover, on the fact that the understudied quality of the problem requires specific attention.

How nurses, through the use of personal narratives, develop and construct meanings around the professionally defined, but personally experienced, event of pregnancy loss. In-depth interviews Value should be attached to emotional work, particularly for nurses working in gynaecological units. The emotional needs have to be fully acknowledged through recognition of the importance of managed emotion in the construction of professional knowledge.

The impact of perinatal death on the healthcare profession is huge. The existing literature focuses on examining perinatal death from parents' perspectives and patient death from the perspectives of nurses and a few doctors in critical care, oncology, and neonatology. The aim is to comprehensively review literature examining the impact of perinatal death on the perspectives of professionals working in maternity units.

The study, via Lazarus and Folkman's transactional model of stress, explores the extent of staff distress, its predictive factors, in nursing and medical staff. Working environment, specifically lack of supervisor support, was significantly correlated with negative coping strategies. Significant levels of subjective distress, staff more vulnerable, opportunity to access support and supervision to mitigate distress and encourage reappraisal of care in case of perinatal death.

A scoping review of published and unpublished data from 1st January 1996 to 5th August 2016.

1) psychological impact, 2) physical impact, 3) positive feelings, 4) coping strategies, 5) personal factors influencing the experience, and 6) cultural factors influencing the experience have been examined as main themes. Healthcare professional have 


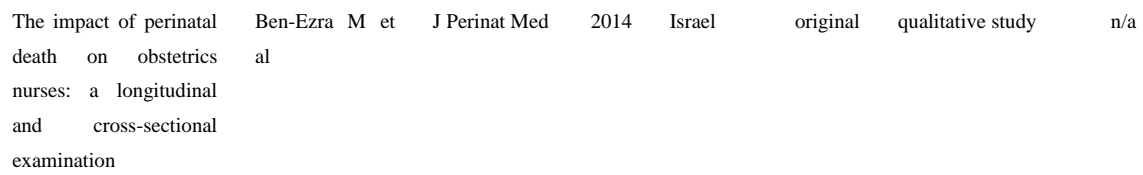

The impact of perinatal loss in maternity units: A psycholinguistic analysis of health professionals' reactions

Gandino G

J Health $2017 \quad$ Italy
Psychol

original

quantitative

linguistic study

The impact of stillbirth

on consultant

obstetrician

gynaecologists: $\quad$ a

qualitative study
Nuzum D, BMJ Journals $2014 \quad$ UK Meaney S, O'Donoghue K.

(a)

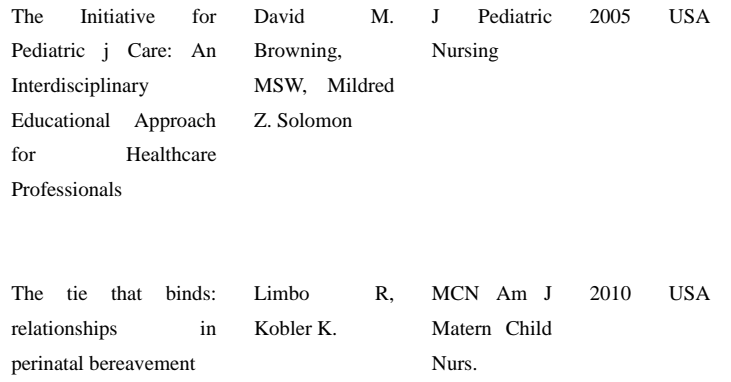

The Initiative for Pediatric j Care: An Interdisciplinary Educational Approach for Healthcare Professionals

David

The tie that binds: relationships in Kobler K. perinatal bereavement

R, MCN Am J 2010 USA Matern Child Nurs.

unmet needs that need to be addressed. Culturally-sensitive education and training are needed. Exposure to perinatal death may add significant stress. Two studies on obstetrics nurses. Study 1: obstetrics nurses showed a higher level of psychiatric symptoms [posttraumatic stress disorder (PTSD), depressive, and psychosomatic symptoms]. Study 2: a higher level of psychiatric symptoms (PTSD, depressive, and psychosomatic symptoms) in the exposed group in comparison to the non-exposed group. The effect of exposure to perinatal death is severe and needs to be addressed by developing intervention and preparation.

Study of the impact of perinatal loss on health professionals language. A linguistic analysis was performed using the Linguistic Inquiry and Word Count software. Associations between language and burnout were studied. Words typical of a psychological shock reaction were used more by non-medical staff than by physicians. Clinical implications of the results are discussed.

Aiming to explore the impact of stillbirth and to research the lived experience of health care consultants in a tertiary university hospital in Ireland. Main findings: personal impact (effecting the provided care for patients) and weight of professional responsibility (professional burden and medico-legal concerns). Need for specialist training in bereavement care.

Methodological study about clinical and educational needs in paediatric palliative care. The analysis, focusing on the needs of parents and professional staff, too, serves as a basis to develop special methods, emotional and cognitive competencies, as well. Relationship is the defining factor, the frame that serves as a base of support for grieving parents. Follow-up support provides care and hope for the families experiencing loss. Professional staff need to find proper ways of self-support and care.

A systematic literary review of the academic writings published between 2005 and 2016 in order to provide an overview of the international research activities. The focus is on the help and 


\begin{tabular}{|c|c|c|c|c|c|c|c|c|c|}
\hline $\begin{array}{l}\text { in prae- and perinatal } \\
\text { care) }\end{array}$ & & & & & & & & & $\begin{array}{l}\text { support healthcare professionals } \\
\text { may have following exposure to } \\
\text { perinatal child loss. }\end{array}$ \\
\hline $\begin{array}{l}\text { Working with } \\
\text { practitioners to develop } \\
\text { training }\end{array}$ & $\begin{array}{l}\text { Pat Cartwright, } \\
\text { Sue Read }\end{array}$ & $\begin{array}{l}\text { Nurse } \\
\text { Education in } \\
\text { Practice }\end{array}$ & 2005 & UK & original & $\begin{array}{l}\text { evaluation of } \\
\text { specialization } \\
\text { programme }\end{array}$ & $\mathrm{a}$ & $\begin{array}{l}21 \text { participants } \\
\text { (nurses, } \\
\text { obstetricians) }\end{array}$ & $\begin{array}{l}\text { Implementation and evaluation of } \\
\text { a formative course for healthcare } \\
\text { staff in perinatal care. }\end{array}$ \\
\hline $\begin{array}{l}\text { in peri-natal loss and } \\
\text { bereavement: }\end{array}$ & & & & & & & & & $\begin{array}{l}\text { The formative model originally } \\
\text { set up for the caregiver nurses was }\end{array}$ \\
\hline $\begin{array}{l}\text { Evaluating } \\
\text { workshops }\end{array}$ & & & & & & & & & $\begin{array}{l}\text { also adapted for the needs of the } \\
\text { mid-wives. }\end{array}$ \\
\hline
\end{tabular}

\section{Copyrights}

Copyright for this article is retained by the author(s), with first publication rights granted to the journal.

This is an open-access article distributed under the terms and conditions of the Creative Commons Attribution license (http://creativecommons.org/licenses/by/4.0/). 